\title{
A SOCIOLOGIA DA EDUCAÇÃO NA FRANÇA: UM PERCURSO PRODUTIVO*
}

\author{
Maria Drosila Vasconcellos ${ }^{* *}$
}

\begin{abstract}
RESUMO: Este artigo apresenta uma síntese de certos trabalhos da sociologia da educação na França. Ele focaliza as abordagens características das orientações e dos conteúdos de estudos sociológicos marcados pelos desafios e metas sociopolíticos que afetam o funcionamento da escola e têm moldado sua construção há quase um século. As principais pesquisas nesse campo sempre tentaram explicar, por um lado, as relaçôes entre a escola e a sociedade francesa e, por outro, as modalidades de organização do sistema educacional e as interaçōes que se estabelecem entre seus diferentes atores.
\end{abstract}

Palavras-chave: Sociologia da educação. Abordagens sociológicas em educação. Escola e sociedade.

\section{SOCIOLOGY OF EDUCATION IN France: A PRODUCTIVE COURSE}

ABSTRACT: This article presents a synthesis of works of the sociology of education, in France. It focuses on the approaches that characterize the orientations and contents of sociological studies marked by the socio-political stakes that affect the functioning of School and have molded its construction for nearly one century. The main researches in this field always tried to explain, on the one hand, the relationships between School and the French society and, on the other, the conditions of organization of the educational system and the interactions that take place among its various actors.

Key words: Sociology of education. Sociological approaches in education. School and society.

* Tradução de Alain François.

** Professora de Sociologia da Educação da Universidade Lille 3 (França). E-mail: vasconcellos@wanadoo.fr

Educ. Soc., Campinas, vol. 24, n. 83, p. 553-573, agosto 2003

Disponível em <http://www.cedes.unicamp.br> 
C nos referirmos a recentes trabalhos teóricos ou empíricos realizados desde os anos 60, na França, a sociologia da educação constitui um dos campos mais produtivos. Vários autores ${ }^{1}$ chamam também a atenção tanto para a importância desses trabalhos, mais particularmente na elaboração de políticas educacionais, como para sua influência sobre a percepção que diversos atores (docentes, funcionários ligados às instâncias ministeriais, pais de alunos etc.) têm das questôes educacionais.

Embora ocupe um lugar importante nos trabalhos de Durkheim, a sociologia da educação desaparece da esfera universitária até os anos 60. Para este autor, o "fato social", definição central em sua teoria, deve muito às características da coerção social das instituiçôes (religião, moral, linguagem, dinheiro...) entre as quais a educação constitui um "operador privilegiado". Por meio da educação, a transmissão dos valores, padrōes e hábitos mentais de uma geração à outra está garantida de modo metódico.

Os trabalhos de Durkheim sobre a relação entre educação e sociologia deixam transparecer sua preocupação ao mesmo tempo "científica" e política. Ao estudar a institucionalização do ensino secundário na França - o collège -, Durkheim (1938) busca não apenas descrever a renovação da ação pedagógica por meio da passagem de uma educação escolástica ao humanismo clássico, mas também explicar a influência exercida pela educação sobre a formação intelectual de novos valores morais e políticos. Assim, Durkheim quer ver na sociologia uma possibilidade de renovação do sistema de crenças religiosas tradicionais rumo a um pensamento embasado em princípios "científicos", que permita ao indivíduo participar de uma nova sociedade, livre de arbitrários e de uma ordem tradicional que, até então, subjugara a sociedade francesa.

Nesse sentido, Durkheim pensa a educação como um meio importante de socialização que espalha valores no conjunto da sociedade, participa ativamente à formação de uma "consciência coletiva" e, assim, se torna um "princípio de integração social".

Posteriormente, o interesse de seus seguidores pela educação tende a esvair-se: a sociologia da educação integra os programas das Escolas Normais e, se alguns discípulos de Durkheim dão seguimento aos trabalhos sociológicos sobre a escola (Cherkaoui, 1979; Geiger, 1979), uma análise dos textos publicados em l'Année Sociologique, criada por Durkheim, revela a ausência de trabalhos atinentes à sociologia da educação, a não ser por algumas resenhas de obras que tratam da educação. ${ }^{2}$ 
Fundamentalmente, os trabalhos de Durkheim têm uma importância considerável, uma vez que, além de fundarem a sociologia da educação na França e no exterior, eles questionam as relaçôes entre ensino e sociedade.

De fato, tanto em suas análises como na aplicação de sua metodologia, os trabalhos de Durkheim permitiam questionar as idéias que norteavam o sistema educacional francês: a neutralidade social da escola gratuita e "aberta a todos", que era considerada como fora do tempo, das estratificaçóes e dos conflitos sociais (Passeron, 1988). Ao tomar a escola como objeto de análise sociológica, ele aborda uma das mais importantes instituições sociais e lança luz sobre a importância das diferenças sociais, função dos pertencimentos socioculturais dos indivíduos, no êxito escolar, na valorização dos diplomas obtidos, na mobilidade social e profissional, entre outros.

Os anos 60 marcam, na França, o início de um período rico em trabalhos sociológicos, em particular sobre o sistema de ensino, inaugurado por um período de vastas enquetes e pelo surgimento de publicações específicas do campo da sociologia da educação. ${ }^{3}$ Tomando por base a periodização, que permite discernir as problemáticas que vêm emergindo desde os anos 60 , foi-nos possível apresentar melhor tanto rupturas/continuidades no campo da sociologia da educação como os motivos que levaram a justaposiçóes ou reorientações nas pesquisas (Van Haech, 1990; Vasconcellos, 2001).

Escola e sociedade: a persistência de uma questão

Desde os anos 60, as relaçóes entre o sistema educacional e a sociedade como um todo são objeto de diversos estudos. Dentro da herança durkheimiana, esses trabalhos enfatizam a importância da escola na reprodução social da sociedade e a complexidade das relaçôes entre um certo tipo de sociedade e um modo de funcionamento do sistema de ensino.

Cabe destacar, aqui, a importância da enquête realizada por Alain Girard et al. (1972), para o Institut National d'Études Démographiques (Instituto Nacional de Estudos Demográficos), sobre uma coorte de alunos durante uns dez anos, que revela os efeitos das diferenças de origens sociais e profissionais dessa população sobre o desenrolar de suas escolaridades (abandonos, repetências, nível e tipo de estudos alcançados etc.). 
A vontade de elaborar teorias explicativas para essas implicaçōes levaram equipes de sociólogos a se interessar pelas modalidades de funcionamento do sistema educacional. De fato, essa enquete de tipo longitudinal levantou várias questóes, uma vez que, à medida que os resultados eram processados, o peso das desigualdades sociais no acesso ao ensino secundário ou entre os fatores que incidem sobre o êxito escolar ficava mais evidente. As diferenças nas origens sociais, profissionais e ainda geográficas dos alunos mostram ter fortes implicaçōes sobre seus percursos escolares.

Essa enquête, que teve muitas repercussões na França, introduzia críticas contra o funcionamento do sistema escolar que ultrapassam os espaços educacionais. Pelo questionamento das idéias recebidas que ela apresenta, essa enquete abre um importante espaço de pesquisas sociológicas.

Os questionamentos levantados pelas modalidades de funcionamento do sistema educacional e pela idéia ilusória de "escola libertadora" despertaram o interesse de vários sociólogos, que elaboraram teorias explicativas sobre as relaçóes entre escola e sociedade.

Assim, Pierre Bourdieu e Jean-Claude Passeron desenvolveram uma análise muito aguçada do sistema de ensino como um importante sistema de auto-reprodução e de reprodução sociocultural, que elucidava as funçôes sociais da escola e da cultura, assim como as relaçōes que existem entre a seleção escolar e a estrutura de classes da sociedade francesa. Ademais, ficava claro que, por meio do trabalho pedagógico realizado pelos docentes, do tipo de conhecimentos transmitidos e de critérios de avaliação fundamentados em dado tipo de expressão ou em práticas de linguagem próprias de certas categorias mais abastadas da sociedade, a escola exerce uma violência simbólica, por sua ação arbitrária, sobre as crianças oriundas dos meios desfavorecidos (Bourdieu \& Passeron, 1970).

Por outro lado, a renovação do marxismo, na França, representada pelos trabalhos de Luis Althusser (1970) em Les appareils idéologiques d'État (Os aparelhos ideológicos de Estado) inspirou várias pesquisas sobre o sistema escolar. A partir de uma análise estatística dos fluxos escolares, Christian Baudelot e Roger Establet (1971) desenvolveram uma teoria sobre o funcionalismo dualista do sistema educacional. Em sua obra L'École capitaliste en France (A escola capitalista na França), esses autores consideram que, longe de ser "único" ou homogêneo e de oferecer chances a todos, o sistema escolar é pro- 
fundamente seletivo e desigualitário, uma vez que, na verdade, ele se assenta em duas redes bem estanques e pouco visíveis para o neófito: uma rede "primária-profissional" destinada a fornecer uma mão-deobra de execução e outra, "secundária-superior", que prepara às funções de concepção e de comando. Apenas uma análise sociológica pôde desvendar a divisão existente na escola, que, embora faça tudo para ocultar o caráter social das dificuldades escolares, sujeita cada geração de alunos a integrar as fileiras do seu meio de origem - burguesia ou proletariado - desde o primário, em razão tanto das demandas de aprendizados como de conteúdos de ensino pouco acessíveis às crianças dos meios populares. Sua obra l'École primaire divise (1975) (A escola primária divide) dá uma excelente apresentação dessa instituição como "máquina de dividir", que transforma "as diferenças em divisão de classes"

No lado oposto, influenciado pelas pesquisas anglo-saxãs fundamentadas em modelizações formais (Lazarfeld, por exemplo), mais particularmente sobre a mobilidade social, Raymond Boudon estudou o funcionamento do sistema escolar a partir de críticas às abordagens macro-sociais, como as usadas pelos trabalhos acima referidos. Em sua obra sobre L'inégalité das chances (1973) (A desigualdade das chances), R. Boudon estuda o funcionamento do sistema educacional a partir de uma análise sociológica do ator que lhe permite mostrar que as "regularidades sociais" representam "a justaposição de uma miríade de comportamentos individuais". Ele se esforça por compreendê-los reconstituindo os motivos que conduzem os indivíduos a fazer escolhas racionais, que levam em conta as coerçóes que pesam sobre a atuação dos indivíduos e que produzem fenômenos sociais diversos. Embasada no individualismo metodológico "que recusa as explicações de tipo funcionalista ou estruturalista", a teoria boudoniana propõe estudar o funcionamento das instituiçóes enquanto "agregação das decisões individuais de atores institucionais". Assim, esses atores fazem escolhas fundamentadas numa racionalidade limitada, pois subordinada à posição social de cada um. Segundo Boudon, as escolhas educacionais ocorrem conforme um cálculo de "custos-benéficios" ou de vantagens. Assim, os estudos universitários não trazem os mesmos benefícios sociais ou profissionais a um jovem oriundo de um meio social abastado ou popular. As escolhas escolares das famílias se dão em função das coerçōes sociais ou escolares. Essas coerçôes estão vinculadas ao meio e são moduladas pela composição social que intervém nos projetos escolares 
mais ou menos ambiciosos dos jovens, dos meios tanto abastados como populares, em função dos custos (inclusive psicológicos) ligados à probabilidade de obter os benefícios esperados de suas escolhas.

Numa outra lógica, nos anos 70 , temos os trabalhos de Viviane Isambert-Jamati, que, numa perspectiva histórica, tratam da questão das evoluçóes do sistema educacional durante as crises sucessivas que o abalam regularmente, e esclarecem a ação dos diversos atores. Ela estudou mais particularmente a categoria dos docentes, na qual percebeu uma oscilação entre uma lógica de reprodução social e de mudança. A pesquisa de Isambert-Jamati, pioneira na França na retomada dos trabalhos iniciados por Durkheim e desenvolvidos pela sociologia anglo-saxã, mas desprezados pelas equipes de sociólogos acima referidas, enfocou os saberes transmitidos na escola e evidenciou a importância de se analisar os conteúdos e os programas escolares. Nos anos 80 , essa temática dos saberes escolares estará no cerne de várias pesquisas em sociologia da educação.

De fato, até o fim dos anos 70, é a questão das desigualdades socioescolares que permanece no cerne das preocupaçóes dos pesquisadores, mais particularmente em razão do aumento da segregação escolar: às desigualdades de acesso ao ensino substituem-se as dos percursos escolares, hierarquizados segundo o valor atribuído aos diplomas escolares que conferem e à composição social de seu público (Duru-Bellat; Van Zanten, 1999). Hoje em dia, a "barreira de nível" não está mais em obter ou não o baccalauréat - diploma de conclusão do segundo grau, importante no sistema educacional francês -, mas no tipo de filière em que este se inscreve: geral, tecnológica ou profissional. É dentro do próprio sistema escolar que as dificuldades se intensificam, mais particularmente pela importância do fracasso escolar.

\section{O deslocamento dos questionamentos: sistema de ensino, escolarização e atores}

As orientações e os conteúdos da pesquisa sociológica sobre o ensino foram regularmente afetados por debates sociopolíticos em que os conhecimentos produzidos pelos pesquisadores têm uma grande influência. A persistência de fortes desigualdades nos percursos escolares, apesar de políticas educacionais que buscam prolongar a escolaridade de todas as crianças, levou os pesquisadores a novos questiona- 
mentos: era preciso apreender não apenas as relações entre a escola e a sociedade em geral, mas também suas modalidades internas de funcionamento, a atuação de diversos profissionais no âmago da instituição educacional e os vínculos que esta estabelece com as famílias e seu meio. A escola continua sendo um desafio sociopolítico complexo e diversificado: ela deve ao mesmo tempo garantir "uma comunhão suficiente de idéias” (Durkheim, 1922), mas também, pela elevação constante do nível da escolaridade das jovens geraçôes, participar da mobilidade socioprofissional da população e favorecer o ingresso na vida ativa.

Ora, desde os anos 80, as políticas que buscam lutar contra “o fracasso escolar" acarretam a emergência de novos estudos sociológicos fundamentados no desempenho dos docentes e dos diretores de estabelecimentos, no trabalho realizado em sala de aula, assim como sobre os saberes escolares e as formas de sua transmissão. Tudo isso num contexto de reformas importantes do sistema de ensino e das demandas dirigidas aos pesquisadores, mais particularmente para melhor explicar os vínculos entre problemas escolares e problemas sociais. Isto não deixou de influenciar o recorte dos campos de pesquisa, a definição dos objetos e os novos procedimentos metodológicos. A idéia de que a unificação do sistema escolar, pelo menos no collège, e o alongamento da escolaridade poderiam remover os obstáculos ao êxito escolar das crianças oriundas de meios sociais desfavorecidos é contestada. Os sistemas explicativos propostos conferem então uma importância decisiva ao discernimento dos momentos-chave da escolarização em que as desigualdades desempenham um papel mais relevante e até mesmo determinante sobre o futuro e merecem assim interpretaçôes por parte dos pesquisadores. É o olhar lançado sobre a construção ao mesmo tempo do cotidiano escolar e da continuidade do processo de escolarização que permite enfatizar a emergência de novas problemáticas, cujo recorte apresentado aqui, embora arbitrário, permite esclarecer as evoluçóes desse campo de pesquisa.

\section{Diversificação das abordagens em sociologia da educação}

No final dos anos 70, a análise da escola é fortemente marcada pelas evoluções da demanda institucional para enfrentar as dificuldades encontradas tanto na organização do sistema educacional como nos debates teóricos que abalam o campo da sociologia - "crise" do marxismo e do estruturalismo e "volta ao ator" - o que leva os pes- 
quisadores a indagar-se sobre as abordagens da sociologia da educação dos anos 60. Considera-se que o interesse pelas estruturas que moldam o sistema educacional pode levar a uma visão determinista da ação da escola e deixar na sombra a importância das práticas individuais ou coletivas que têm uma influência sobre as inovações ou mudanças ocorridas no sistema de ensino. Vários trabalhos se dedicam assim a tratar os efeitos das políticas dentro das instituições consideradas como micro-sistemas organizados, como lugares de interaçôes, o que permite fugir das tendências pesadas das estruturas e oferece margens de manobra aos atores. Dá-se importância ao local ou ao singular e às interações entre vários atores nos estabelecimentos escolares e em seu meio.

Os dados estatísticos, que o Ministério pretendia usar na gestão dos fluxos de alunos para assim deitar as bases das políticas educacionais, permitiram aos pesquisadores elucidar as regularidades sociais analisadas. Nessa nova fase, as preocupaçōes dos pesquisadores modificam-se: eles se esforçam por explicar o processo das diferenciações dos percursos escolares e da singularidade das situações, assim como por descrever de maneira mais aguçada os fenômenos educacionais. Recorre-se a procedimentos oriundos da etnografia, a técnicas de observação, a monografias ou estudos de casos (Reynaud, 2002). $\mathrm{O}$ ator é então considerado como portador de mudanças no sistema educacional (Coulon, 1988). Dessa forma, a pesquisa permite dar conta do vínculo entre teoria e prática e também da diversidade das práticas e de seus efeitos. Contudo, as transformações quantitativas do sistema de ensino permanecem muito importantes e conduzem os sociólogos da educação a levar em conta ao mesmo tempo sua amplidão e suas conseqüências.

\section{As desigualdades sociais e os percursos escolares}

O grande número de trabalhos que aborda as diferenças das trajetórias forneceu elementos importantes sobre as modalidades de funcionamento do sistema escolar. Já no ingresso na escola maternal, é possível perceber a importância da escolarização precoce no destino escolar das crianças, uma vez que esta facilita a adaptação e a familiarização com as exigências escolares (Plaisance, 1986). O interesse pela educação da prima infância vai de par com a receptividade, por parte de pais de classe média, de certas teorias educacionais, o que desloca o interesse para o desenvolvimento de capacidades de 
desabrochamento, por exemplo, que possam favorecer mais tarde as aprendizagens cognitivas e simbólicas.

Por outro lado, as desigualdades das trajetórias analisadas evidenciam discriminaçōes de ordem sexual: apesar da igualdade formal de acesso dos garotos e garotas a todos os níveis de ensino, as garotas continuam sub-representadas nas filières seletivas e prestigiosas. Embora sua taxa de êxito seja superior à dos garotos, seus resultados são inferiores em Matemática, disciplina que, na França, desempenha um papel seletivo na orientação para as filières mais prestigiosas. $\mathrm{O}$ fato de o sentido comum atribuir às garotas uma inaptidão para a Matemática pode explicar parcialmente sua defecção nessa disciplina, junto com o conformismo ou os estereótipos sociais que continuam imperando nas práticas diferenciadas dos docentes, nos projetos dos pais ou nos papéis sociofamiliares atribuídos aos garotos e às garotas (Baudelot-Establet, 1992; Duru-Bellat, 1990; Mosconi, 1994).

A outra variável importante nas diferenças de percursos liga-se às origens por nacionalidade: as crianças nascidas no exterior ou de famílias de origem estrangeira apresentam globalmente trajetórias marcadas por fracassos escolares. Entretanto, é preciso enfatizar que, como a maioria dessas crianças tem origens sociais modestas, seus resultados são muito próximos dos das crianças de origem francesa que têm as mesmas origens socioprofessionais. A enquete desenvolvida pelo INED (Girard, 1972) constatava esse fato, pois esses alunos acumulam características sociais e culturais associadas às situações de fracasso escolar. Ademais, as crianças de origem estrangeira cujos pais são trabalhadores qualificados apresentam às vezes resultados melhores do que as francesas de nascimento (Vallet; Caillet, 1996). Aqui, a mobilização familiar parece desempenhar um papel relevante, pois dentre as crianças oriundas de famílias imigradas, o êxito nos estudos cumpridos varia segundo o nível de expectativas, os investimentos e a posição social da família no país de origem (Zeroulou, 1988; Van Zanten; Grospiron; Kherroubi; Zeroulou, 2002).

Entretanto, a questão do fracasso escolar das crianças de origem social modesta analisa-se também pelas disparidades geográficas e regionais, mesmo se estas vêm evoluindo muito há três décadas. De fato, as pesquisas em educação sempre mostraram diferenças entre regiôes, mas particularmente em razão da clivagem entre rural e urbano e entre certas influências culturais locais etc. Atualmente, entretanto, privilegia-se a diversidade da oferta de formação em nível local (por exemplo, a decisão de desenvolver escolarizações 
de técnicos superiores, especialidades de baccalauréat profissional, abertura de certas opçôes para o baccalauréat geral, entre outros). Resta, contudo, a questão do vínculo muito estreito entre a segregação urbana e a segregação escolar: as características sociais das populações atuam em força sobre os resultados escolares (desemprego, desestruturação da organização familiar etc.) (Davaillon; CEuvrard, 1998; Van Zanten, 2001, 2002).

\section{$O$ estabelecimento escolar e seus efeitos}

Hoje em dia, o êxito dos alunos parece depender muito das condiçôes sociais em que a escolaridade das crianças ocorre. Várias pesquisas, desde a desenvolvida pelo INED, mostraram que as desigualdades escolares não se constroem apenas pelas diferenças sociais dos pais, mas dentro dos próprios estabelecimentos e salas de aula. A análise dos estabelecimentos escolares enquanto organização dotada de lógicas de atores, de distribuição de autoridade ou de poder - formal ou informal - contribui a revelar, nesse nível, sua eficácia própria, independente de seu recrutamento social e escolar. Desde os anos 80 , multiplicam-se os trabalhos que buscam melhor apreender os efeitos das políticas nacionais de descentralização, da promoção dos estabelecimentos escolares secundários a uma certa autonomia de funcionamento e das políticas institucionais que buscam discernir tanto as modalidades de organização do trabalho escolar como as práticas de seus atores (Bressoux, 1996; Cousin, 1993). Alguns trabalhos explicaram a possibilidade de se desenvolver vários tipos de lógica dentro de uma mesma instituição escolar: desabrochamento da criança, busca de eqüidade, de desempenho, de eficiência inspirada nos modelos empresariais (Derouet, 1992). Como ocorrem interaçôes entre docentes e alunos, entre estes, as famílias e instituiçōes locais outras que de ensino, essas análises das práticas dos atores, dentro do estabelecimento e de seus relações com o meio, permitem identificar o processo de construção de interaçôes entre atores individuais e coletivos, assim como o peso das coerçôes estruturais. As desigualdades, que persistem dentro da escola, apesar do alongamento da escolaridade, têm orientado as políticas públicas educacionais para uma descentralização e seu recorte geográfico em "áreas de educação prioritárias" localizadas em bairros "difíceis", que acumulam dificuldades socioeconômicas (Plaisance, 1985). Os estabelecimentos 
escolares secundários são instados a elaborar projetos de estabelecimentos que empenhem a "comunidade educacional" a alcançar objetivos de eficiência, em função dos quais recursos são alocados para seu "bom funcionamento" (Meuret, 1994). Junto com a ampliação das práticas de avaliação, que permitem classificar os estabelecimentos segundo seu desempenho, essa política induziu a implementação de estratégias de concorrência entre estabelecimentos e, por parte das famílias, comportamentos de "consumidores", que evitam os bairros "problemáticos" e transgridem o princípio do mapa escolar (inscrever seus filhos no estabelecimento mais próximo de seu domicílio) (Ballion, 1982; Tripier, Léger, 1986). Além das disparidades geográficas ou regionais, os estabelecimentos escolares apresentam resultados variados. Enquetes realizadas nos bairros de várias cidades francesas observam que o contexto de escolarização desempenha um papel relevante nas diferenças sociais de êxito escolar. Alunos de um mesmo meio social e de mesmo nível escolar progridem diferentemente segundo o colégio em que se inscrevem: os docentes podem ser mais ou menos "severos" segundo os objetivos ou as políticas do estabelecimento (Duru-Bellat; Mingat, 1998). Ademais, como os pais são mais informados sobre o "bom funcionamento" de um estabelecimento, eles intervêm para garantir a "boa" reputação do estabelecimento, condicionada pelo ambiente que nele reina e pela luta contra a desordem escolar (violências, degradações, incivilidades diversas) (Debarbieux, 1998). Isso conduz à construção de um "mercado" escolar estreitamente vinculado às condiçôes da vida urbana. Assim, algumas famílias escolhem seu lugar de residência em função da qualidade dos estabelecimentos escolares locais (Broccolichi, 1997; Barthon; Oberti, 2000; Ballion, 1991). Por outro lado, algumas pesquisas demonstram que, dentro de um mesmo estabelecimento, existem segregações por classes de "nível". Para preservar uma boa reputação e tranqüilizar os pais, os colégios, que devem apresentar uma unidade de ensino, organizam o reagrupamento de certos alunos em classes de nível, mais particularmente pelo viés de opções de línguas vivas ou antigas oferecidas (latim, russo etc.) (Trancart, 1998; Duru-Belat; Mingat, 1997; Payet, 1998; Van Zanten, 2000).

Os efeitos da política educacional de descentralização e de criação de "áreas de educação prioritária" introduzem assim a idéia de "discriminação positiva" (dar mais aos que têm menos) e instauram diferenças sensíveis vinculadas à localização geográfica dos estabele- 
cimentos. Esses efeitos favorecem a emergência de um "mercado escolar" em que as concorrências transformam os pais em "estrategistas" que escolhem estabelecimentos e filières e intervêm no funcionamento dos estabelecimentos enquanto usuários ou consumidores (Ballion, 1982).

Outros efeitos vinculados às transformações das políticas educacionais, como a ampliação das práticas de avaliação, permitem às instâncias ministeriais acompanhar e até mesmo controlar o funcionamento dos estabelecimentos e os resultados escolares dos alunos. Isto gerou trabalhos importantes sobre os efeitos dessas orientaçōes (Merle, 1996; Thélot; Vallet, 2000) Essas pesquisas focalizaram mais particularmente sua atenção sobre as desigualdades que perduram e se somam às da democratização escolar efetiva (DuruBellat; Merle, 2000; Dubet; Martucceli, 1996; Langoët, 2000).

\section{O corpo docente e a relação ao oficio}

O alongamento da escolarização impôs o recrutamento maciço de docentes em todos os níveis de ensino. Ora, isso acarretou uma transformação profunda das modalidades de recrutamento, das condiçōes de acesso ao ofício e das formaçōes e do exercício da profissão docente. Longe de constituir um grupo profissional homogêneo, os docentes se distinguem ao mesmo tempo pelo nível de ensino em que exercem (primário, secundário ou superior), de estatuto, de formação, de funçôes etc. A sociologia da educação interessou-se mais particularmente pela constituição desse grupo profissional: sua estrutura de classe (heterogeneidade das origens sociais), suas atividades extra-escolares, suas atitudes e práticas em seu meio de trabalho (Berger, 1979; Chapoulie, 1987), sua formação tanto nas antigas escolas normais (Delsaut, 1992) como nos atuais Instituts Universitaires de Formation des Maîtres (Institutos Universitários de Formação dos Mestres - IUfms) (Trousson, 1992; Cacouault, 2001). Confrontados com as dificuldades de públicos escolares que têm trajetórias escolares desigualmente distribuídas e com o exercício do ofício ou da profissão docente, os docentes buscam, pela mobilidade geográfica, ter acesso a estabelecimentos melhor reputados pela sua "excelência escolar". Eles reforçam assim as idéias de discriminação negativa dos estabelecimentos devida às origens sociais e geográficas de seus alunos. Notam-se então atitudes diversas diante dessas dificuldades: uns fazem mostra de conserva- 
dorismo social e escolar voltado para um passado nostálgico e se fecham sobre si mesmos. Outros persistem num engajamento positivo e em tentativas de inovação. Por outro lado, observa-se que esses tipos de comportamentos estão estreitamente vinculados ao tempo de serviço (os mais jovens se engajam mais em estratégias de mudanças) e às diferenças sexuadas (as mulheres, sem distinção de faixa etária, são mais favoráveis a inovaçôes) (Cacouault, 1995, 1999). Entretanto, os conflitos entre a administração e os docentes costumam dizer respeito às dificuldades em definir suas competências profissionais. As dificuldades em "dar aula" para um público "difícil" implicam não apenas transmitir conhecimentos e saberes, mas também garantir a disciplina, o "clima social", a educação "moral” e preparar para o emprego (Demailly, 1991; 1993). O trabalho efetivo realizado pelos docentes é também analisado mediante tarefas precisas: preparação das aulas, realização do curso, exercícios pedagógicos, controles e avaliações, correções de provas e de exames (Barrère, 2002).

\section{Os saberes escolares, os programas e os conteúdos de ensino}

Desde o trabalho de Durkheim (1938) sobre l'évolution pédagogique en France (A evolução pedagógica na França), a questão da distribuição dos saberes escolares é objeto de pesquisas sociológicas. Nos anos 70, nessa perspectiva sócio-histórica, IsambertJamati busca tratar a questão do sentido conferido aos saberes transmitidos pelos docentes segundo os valores que orientam suas ações, o contexto social e temporal do exercício de sua profissão e as funções prescritas ao ensino pelas relações entre a escola e a sociedade. Nos anos 80, a ênfase recai sobre as condições de elaboração dos programas e dos conteúdos de ensino. Na França, inspiradas por trabalhos anglo-saxões sobre a sociologia do currículo (Forquin, 1990), várias pesquisas ligam as práticas dos docentes ao tipo de público para o qual cumprem sua missão (Isambert-Jamati, 1990; Plaisance, 1986; Rayou, 2000). A questão das relações entre os saberes transmitidos, as normas impostas à escola e a socialização no meio familiar surgem como tema de vários estudos sociológicos (Forquin, 1989; Lahire, 1993; Charlot, 1987). Alguns sociólogos adotam uma abordagem antropológica sobre as relações de interdependência entre as configuraçóes familiares populares e a escola (Lahire, 1995). Charlot, por seu lado, alerta contra práticas docen- 
tes que "confinam" os alunos em seu universo cotidiano sob pretexto de adaptar os estabelecimentos populares ao público. O que importa é a relação com o saber que esses alunos e suas famílias mantêm com a escola: o interesse pelos estudos torna-se puramente instrumental, dirigido à obtenção de um diploma, seguido pelo acesso a um emprego (Charlot, 1987, 1997).

\section{Educação e inserção profissionais}

Desde os anos 60, na França, a vontade de amarrar o sistema educacional ao sistema produtivo, pelo viés das qualificações da mãode-obra juvenil que entra no mercado de trabalho, favoreceu o surgimento de um questionamento entre escola e trabalho. Os dados fornecidos por diversas instâncias públicas, como o Ministério da Educação ou organismos criados para acompanhar a passagem dos fluxos escolares ao emprego (CEREQ, CEE), assim como o processamento dos resultados dos censos da população francesa, podem esclarecer a relação entre o nível de formação da população e o volume de empregos disponíveis. Essa acumulação de dados favoreceu o interesse dos pesquisadores para a relação entre formação e emprego (Agulhon, 1997; Vasconcellos, 2003). A associação da sociologia da educação e do trabalho leva a constituir um campo de pesquisa caracterizado em termos de inserção profissional: longe de representar um processo contínuo e linear de passagem da escola ao emprego, a inserção surge como um período particular, organizado pelas diversas instâncias do Estado, que combina períodos de emprego, de desemprego, de formação profissional até o momento em que o jovem tem acesso a um emprego estável e se beneficia de um estatuto profissional (NicoleDrancourt; Roulet-Berger, 1998). Ora, as enquetes nesse campo mostraram que as situaçôes variam em função das características individuais e sociais dos jovens, do estado do mercado de trabalho (local ou nacional) e das políticas das empresas. Aqui, apesar das taxas elevadas de diplomados em situação de desemprego, o nível e o tipo de diploma obtido parecem exercer uma proteção contra os percalços do mercado de trabalho (Goux; Marin, 1997). As pesquisas realizadas com os jovens egressos do sistema educacional, durante esse período de inserção, revelam uma forte influência das dificuldades familiares (ter pais desempregados, por exemplo) e da valorização das capacidades ou competências reconhecidas pelos empregadores. Ora, o ensino profissional organiza-se cada vez mais segundo o "modelo de compe- 
tências": os programas escolares são nele elaborados na base de um referencial de formação estreitamente vinculado a um referencial de emprego elaborado por representantes dos meios empresariais. $\mathrm{O}$ modelo pedagógico preconizado é o da alternância que inclui a aquisição de conhecimentos práticos em empresa (num meio de trabalho real) e teórico-práticos em colégios profissionais (Ropé; Tanguy, 1994). Mais do que uma adequação formação-emprego, as pesquisas nesse campo criticam por um lado a maneira como certos alunos (em dificuldade escolar) são orientados para esse tipo de instituições, sua "desclassificação" social devida ao estatuto epistemológico dos saberes e a forma pela qual estes são adquiridos pelos alunos.

\section{Conclusão}

As problemáticas que compõem o panorama da sociologia da educação, na França, mostram ao mesmo tempo uma continuidade e uma vontade de aprofundar dados fenômenos ou processos vinculados à escolarização, assim como a atuação das diversas categorias de atores dentro da escola. A centralidade do sistema de ensino nas políticas públicas para garantir a "igualdade das chances" a todos, por parte dos tomadores de decisão políticas, acarretou, por um lado, o interesse do investigador em romper com a ilusão da "escola libertadora". Foi a base dos trabalhos sobre as razões da desigualdade escolar atribuída, num primeiro tempo, às condições sociais da escolarização e ao contexto social em que ocorre a ação educacional. Por outro lado, dentro da própria escola, existe uma busca dessas condições de êxito escolar. O agravamento da crise social e econômica que se traduz por um desemprego elevado, mais particularmente entre os jovens de origens sociais mais modestas, mas, hoje em dia, também entre os de famílias de classe média, trouxe uma crença imperecível nas virtudes da escola para garantir o futuro socioprofissional das crianças. Entretanto, instada a remediar todos "os males" de dadas categorias da população, a escola se esgota perseguindo objetivos que estão fora de seu alcance. Importa, contudo, analisar as modalidades de funcionamento do sistema de ensino que contribui, de algum modo, para intensificar as dificuldades de certas categorias de alunos pouco propensos a aderir à "forma escolar" dominante (Vincent, 1994). Tanto mais que, desde os anos 90, a questão social vem se exacerbando e leva as camadas sociais mais desprovidas a uma situação de exclusão. Assim, em vários bairros e municípios, a escola se torna a úl- 
tima instituição que garanta o vínculo social, permita escapar da "fatalidade do fracasso" e favoreça a inserção social e profissional. Entretanto, as pesquisas sociológicas sobre a escolaridade demonstram a complexidade das dinâmicas sociais, a interdependência dos diferentes fatores e os efeitos inesperados das políticas educacionais, que confinam os trabalhos sociológicos desse campo a uma reflexão crítica e pouco propensa a fornecer as perícias desejadas por diferentes tomadores de decisão.

O tema da socialização, da relação entre freqüentar a escola e manter o vínculo social, é muito atual. As críticas dirigidas à escola quanto a sua capacidade de dotar os jovens de competências utilizadas no mercado de trabalho, quanto à desconsideração do valor universal dos saberes transmitidos e quanto a sua capacidade de garantir as possibilidades de mobilidade social revelam, por outro lado, a importância conferida a essa instituição. De fato, ela se confronta com a injunção de continuar garantindo, de modo simbólico ou real, o papel de integração social, sobre o qual Durkheim fundamentou sua concepção da escola, papel que, hoje em dia, se vê novamente questionado e valorizado.

\section{Recebido em abril de 2003 e aprovado em junho de 2003.}

\section{Notas}

1. A esse respeito, ver os textos que analisam o desenvolvimento da sociologia da educação na França, apresentados por V. Isambert-Jamati (1984); J-C. Passeron (1988); L. Tanguy (1995) e A. Van Zanten (2000).

2. Segundo M. Cherkaoui, o número de trabalhos sobre os sistemas de ensino, na França e no exterior, entre 1898 e 1914, é considerável e o fato de Durkheim não levar essa produção em consideração pode se dever às difíceis relaçôes, naquela época, entre várias disciplinas e, em particular, entre sociologia e psicologia ou entre sociologia e ciências da educação.

3. Os trabalhos em sociologia da educação são publicados nas principais revistas sociológicas, mas também em revistas especializadas em educação, algumas das quais se devem a iniciativas ministeriais.

\section{Referências bibliográficas}

AGULHON, C. La relation formation et emploi: une synthèse des travaux réalisés. Carrefours de l'Éducation, Amiens, n. 4, 1997.

ALTHUSSER, L. Les appareils idéologiques d'État. La Pensée, Paris, 1970. 
BALLION, R. Les consommateurs d'école. Paris: Stock, 1982.

BALLION, R. La bonne école. Paris: Hatier, 1991.

BARRÈE A. Les enseignants au travail. Paris: l'Harmattan, 2002.

BARTHON C.; OBERTI M. Ségrégation spatiale et évitement et choix des établissements. In: VAN ZANTEN, A. (Dir.). L'école, état de savoirs. Paris: La Découverte, 2000.

BAUDELOT, C.; ESTABLET, R. L'école capitaliste en France. Paris: Maspéro, 1971.

BAUDELOT, C.; ESTABLET, R. L'école primaire divise. Paris: Maspéro, 1975.

BAUDELOT, C.; ESTABLET, R. Allez les filles! Paris: Seuil, 1992.

BERGER, I. Les instituteurs, d'une génération à l'autre. Paris: PUF, 1979.

BOUDON, R. Linégalité des chances. Paris: PUf, 1973.

BOURDIEU, P.; PASSERON, J.-C. La reproduction. Paris: Minuit, 1970.

BRESSOUX, P. Les recherches sur les effets-écoles et les effetsmaitres. Revue Française de Pédagogie, Paris, n. 108, 1996.

BROCCOLICHI, S. L'école dans la ville. Annales de la Recherche Urbaine, Paris, n. 75, 1997.

CACOUAULT, M. Images, carrières et modes de vie des enseignantes: des années 60 à 90. Recherche et Formation, Paris, n. 20, 1995.

CACOUAULT, M. Les professeurs du secundaire: une profession féminine. Genèse, Paris, IRESCO/CNRS, n 36, 1999.

CACOUAULT, M. La féminisation signifie-t-elle une baisse de prestige? Travail, Genre et Société, Paris, IRESCO/CNRS, n. 5, 2001.

CACOUAULT, M.; OEUVRARD, F. La sociologie de l'éducation. Paris: La Découverte, 2001.

CHAPOULIE, J.-M. Les professeurs de l'enseignement secondaire, un métier de classe moyenne. Paris: Maison des Sciences de l'Homme, 1987.

CHARLOT, B. L'école en mutation. Paris: Payot, 1987. 
CHARLOT, B. Du rapport au savoir: éléments pour une théorie. Paris: Anthropos, 1997.

CHERKAOUI, M. Modèles de démocratie et types d'école. In: Boudon, R. et al. École et société: les paradoxes de la démocratie. Paris: PUF, 2001.

COUlON, A. Ethnométhodologie et éducation. Revue Française de l'Éducation, Paris, n. 82, 1988.

COUSIN, O. L'effet établissement: construction d'une problématique. Revue Française de Sociologie, Paris, v. 34, n. 3, p. 395-419, 1993.

DAVAILLON, A.; OEUVRARD, F. Réussit-on à l'école rurale? Cahiers Pédagogiques, Paris, v. 53, n. 365, 1998.

DEBARBIEUX, E. La violence en milieu scolaire. Paris: ESF, 1998.

DELSAUT, Y. La place du maître. Paris: l'Harmattan, 1992.

DEMAILLY, L. Le collège: crises, mythes et métiers. Paris: Presses universitaires de Lille, 1991.

DEMAILLY, L. L'évolution actuelle des méthodes de mobilisation et d'encadrement des enseignants. Savoirs, Paris, n. 1, 1993.

DEROUET, J.-L. École et justice: de l'égalité des chances aux compromis locaux? Paris: Metailié, 1992.

DUBET, F.; MARTUCCELLI, D. A l'école, sociologie de l'expérience scolaire. Paris: Seuil, 1996.

DURKHEIM, E. Éducation et sociologie. Paris: PUF, 1922.

DURKHEIM, E. L'évolution pédagogique en France. Paris: PUF, 1938.

DURU-BELLAT, M.; VAN ZANTEN, A. Sociologie de l'école. Paris: Armand Colin, 1999.

DURU-BELLAT, M.; MERLE, P. Politiques éducatives, évolution de scolarités et transformations de la sélection scolaire. Année Sociologique, Paris, v. 50, n. 2, 2000.

DURU-BELLAT, M.; MINGAT, A. La constitution des classes de niveau dans les collèges: les effets pervers d'une politique à visée égalisatrice. Revue Françase de Sociologie, Paris, XXXVIII/3, 1997. 
DURU-BELLAT, M. L'école des filles. Quelles formations pour quels rôles sociaux? Paris: l'Harmattan, 1990.

FORQUIN, J.-C. L'École et la culture. Bruxelles: De Boeck, 1989.

FORQUIN, J.-C. Sociologie des inégalités d'éducation. In: Hassenforder, J. Sociologie de l'éducation: dix ans de recherches. Paris: l'Harmattan, 1990.

GEIGER, R. La sociologie dans les écoles normales primaires. Histoire d'une controverse. Revue Franaçsie de Sociologie, Paris, XX/1, 1979.

GIRARD, A. Population et l'enseignement. Paris: INED; PUf, 1972.

GOUX, D.; MARIN, E. Destinées sociales: rôle de l'école et du milieu d'origine. Économie et Statistiques, Paris, n. 306, p.13-26, 1997.

HENRIOT, A.; VAN ZANTEN, A.; THIN, D.; VINCENT, G. Processus de formation et dynamiques locales dans l'agglomération lyonnaise. Paris: Université Lumière Lyon 2, 1992.

ISAMBERT-JAMATI, V. Culture technique et critique sociale à l'école. Paris: PUF, 1984.

ISAMBERT-JAMATI, V. Les savoirs scolaires. Paris: PUF, 1990.

LAHIRE, B. Culture écrite et inégalités sociales, sociologie de l'échec scolaire. Paris: Presse universitaire de Lyon, 1993.

LAHIRE, B. Tableaux de familles. Paris: Gallimard; Seuil, 1995.

LANGOËT, G. La démocratisation de l'enseignement d'aujourd'hui. Paris: ESF, 1994.

LANGOËT, G.; LEGER, A. Public ou privé? Trajectoires et réussites scolaires. Paris: Publications de l'Espace européen, 1991.

MERLE, P. L'évaluation des élèves. Paris: PUF, 1996.

MEURET, D. L'efficacité des politiques des ZEP dans les collèges. Revue Française de Pédagogie, Paris, n. 109, 1994.

MOSCONI N. Femmes et savoir: la société, l'école et la division sexuelle des savoirs. Paris: l'Harmattan, 1994.

NICOLE-DRANCOURT, C.; ROULLET-BERGER, L. L'insertion des jeunes en France. Paris: PUF, 1998 
PASSERON, J.-C. L'école et l'enseignement. In: Mendras, H.; Verret, M. Les champs de la sociologie française. Paris: Armand Colin, 1988.

PAYET, J.-P. La ségrégation scolaire. Revue Française de Pédagogie, Paris, n. 123, 1998.

PLAISANCE, E. L'échec scolaire. Paris: CNRS, 1985.

PLAISANCE, E. L'enfant, la maternelle, la société. Paris: PUF, 1986.

RAYOU, P. Les savoirs scolaires. Année Sociologique, Paris, v. 50, n. 2, 2000.

REYNAUD, J.-D. L'innovation, entre régulation et anomie. In: CROS, F. (Dir.). Politiques de changement et pratiques de changement. Paris: INRP, 2001. p.68-71.

ROPPÉ, F.; TANGUY, L. Savoirs et compétences. Paris: l'Harmattan, 1994.

SIROTA, R. L'école primaire au quotidien. Paris: PUF, 1988.

THÉLOT, C.; VALLET, L.-A. La réduction des inégalités sociales devant l'école depuis le début du siècle. Économie et Statistiques, Paris, n. 334, 2000.

TRANCART, D. Lévolution des disparités entre collèges publics. Revue Française de Pédagogie, Paris, n. 124, 1998.

TRIPIER, M.; LEGER, A. Fuir ou construire l'école populaire? Paris: Méridiens, 1986.

TROUSSON, A. De l'artisan à l'expert, la formation des enseignants en question. Paris: Hachette, 1992.

VALLET, L.-A.; CAILLET, J.-P. Les enfants étrangers ou issus de l'immigration dans l'école française. Dossier d'Éducation et Formation, Paris, 1996.

VAN HAECHT, A. L'école à l'épreuve de la sociologie. Bruxelles: De Boeck, 1990.

VAN ZANTEN, A. École: état des savoirs. Paris: La Découverte, 2000.

VAN ZANTEN, A. L'École de la périphérie. Paris: PUF, 2001. 
VAN ZANTEN, A. Massification et régulation du système d'enseignement: adaptations et ajustements en milieu défavorisé. Année Sociologique, Paris, v. 50, n. 2, 2001.

VAN ZANTEN, A. et al. Quand l'école se mobilise: les dynamiques dans les établissements de banlieue. Paris: La dispute, 2002.

VASCONCELLOS, M. L'éducation et la question de l'emploi. Revue Française de Pédagogie, Paris, INRP, à paraître, 2003.

VASCONCELLOS, M. Le système éducatif. 3. ed. Paris: La Découverte, 2001.

VASCONCELLOS, M. Le diplôme, un enjeu social. Projet, 341, dec. 1994.

VINCENT, G. L'école, prisonnière de la forme scolaire: scolarisation et socialisation dans les sociétés industrielles. Paris: Presses universitaires de Lyon, 1994.

ZEROULOU, Z. La réussite des enfants d'immigrés. Revue Française de Sociologie, Paris, v. 29, 1988. 